\title{
Iron Isomaltoside 1000
}

\author{
National Cancer Institute
}

\section{Source}

National Cancer Institute. Iron Isomaltoside 1000. NCI Thesaurus. Code C92584.

An intravenous colloidal solution containing trivalent iron ( $\mathrm{Fe} 3+)$ chelated to isomaltosides, used as iron replacement. The iron in iron isomaltoside 1000 is strongly bound to the carbohydrate particles; each particle contains a trivalent iron core and a carbohydrate shell of isomaltosides which protects and stabilizes the iron core. This results in low levels of free iron and decreases inorganic, unbound iron-related toxicities thereby allowing for administration of higher doses of iron as compared to other ironcontaining formulations. Upon parenteral administration and deg radation of the carbohydrate shell, the iron in iron isomaltoside 1000 is released and replenishes iron stores. 